\title{
Low-order dynamic modeling of cryogenic distillation columns based on nonlinear wave phenomenon
}

\author{
Guang-Yan Zhu ${ }^{\mathrm{a}, 1}$, Michel A. Henson ${ }^{\mathrm{a}, *}$, Lawrence Megan ${ }^{\mathrm{b}}$ \\ a Department of Chemical Engineering, Louisiana State University, 110 Chemical Engineering Bldg. Baton Rouge, \\ LA 70803-7303, USA \\ b Process and Systems, Research and Development, Praxiar, Inc. Tonawanda, NY 14151-0044, USA
}

Received 14 November 2000; received in revised form 2 April 2001; accepted 3 April 2001

\begin{abstract}
A low-order dynamic model based on nonlinear wave theory is developed for a cryogenic distillation column used for nitrogen purification. By tracking the wave front propagating through the column, a simple mathematical model capable of describing the essential column dynamics is derived. The combined reboiler/condenser system is modeled using rigorous mass and energy balances. The low-order model is compared with a first-principles model developed with the commercial simulator HYSYS.Plant (Hyprotech) and is found to produce satisfactory predictions over a large range of operating conditions. The simulation results illustrate potential limitations of the assumptions used in the wave model development. On-line model adaptation is proposed as a possible approach to overcome the constant wave shape assumption. Extensions for multiple column modeling and nonlinear system design are also discussed. (C) 2001 Elsevier Science B.V. All rights reserved.
\end{abstract}

Keywords: Cryogenic distillation; Air separation; Dynamic modeling; Nonlinear wave models

\section{Nomenclature}

$\begin{array}{ll}B & \text { dimensionless mass transfer coefficient } \\ F & \text { feed air flow rate }(\mathrm{kmol} / \mathrm{h}) \\ F_{G N_{2}} & \text { gas nitrogen production rate }(\mathrm{kmol} / \mathrm{h}) \\ F_{L} & \text { returning liquid stream flow in reboiler }(\mathrm{kmol} / \mathrm{h}) \\ F_{L N_{2}} & \text { liquid nitrogen production rate }(\mathrm{kmol} / \mathrm{h})\end{array}$

\footnotetext{
* Corresponding author. Tel.: + 1-225-3883690; fax: + 1-225-3881476.

E-mail address: henson@che.lsu.edu (M.A. Henson).

${ }^{1}$ Present address: Advanced Process Control, Global Supply System (GSS), Praxair, Inc., Tonawanda, NY 14151-0044, USA.
} 


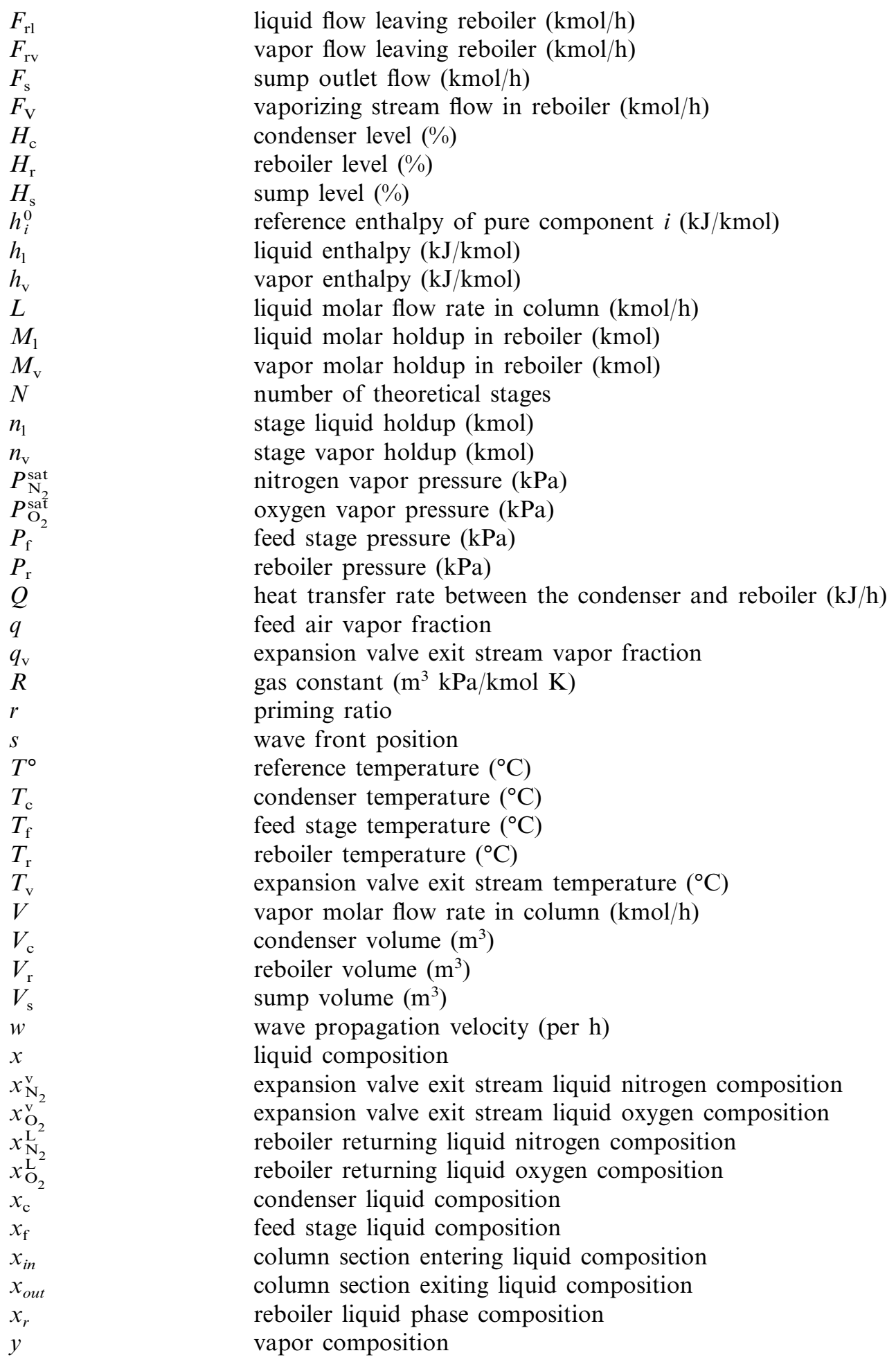




$\begin{array}{ll}y^{*} & \text { equilibrium vapor composition } \\ y_{\mathrm{N}_{2}}^{\mathrm{v}} & \text { expansion valve exit stream vapor nitrogen composition } \\ y_{\mathrm{O}_{2}}^{\mathrm{v}} & \text { expansion valve exit stream vapor oxygen composition } \\ y_{\mathrm{N}_{2}}^{\mathrm{v}_{2}} & \text { reboiler vaporizing stream nitrogen composition } \\ y_{\mathrm{O}_{2}}^{\mathrm{V}_{2}} & \text { reboiler vaporizing stream oxygen composition } \\ y_{\mathrm{in}} & \text { column section entering vapor composition } \\ y_{\text {out }} & \text { column section exiting vapor composition } \\ y_{\min } & \text { concentration limit as } \mathrm{z} \rightarrow-\infty \\ y_{\max } & \text { concentration limit as } \mathrm{Z} \rightarrow+\infty \\ y_{\mathrm{r}} & \text { reboiler vapor phase composition } \\ z & \text { dimensionless spatial coordinate } \\ z_{\mathrm{f}} & \text { feed air nitrogen composition } \\ \alpha & \text { relative volatility } \\ \gamma & \text { wave front slope } \\ \tau & \text { dimensionless time coordinate } \\ \xi & \text { wave coordinate }\end{array}$

\section{Introduction}

Cryogenic distillation is used to produce large quantities of purified nitrogen, oxygen and argon for the steel, chemical, food processing, semiconductor and health care industries. Cryogenic distillation columns are operated at extremely low temperatures $\left(-170\right.$ to $\left.-190^{\circ} \mathrm{C}\right)$ to separate air components according to their different boiling temperatures. The purified streams are produced in liquid and/or gaseous states for transportation to end-users. The major operational cost associated with cryogenic air separation plants is electricity. The domestic consumption of electricity by industrial gas producers is over $\$ 700$ million per year. Therefore, small improvements in process control have the potential to result in substantial economic benefits. Current control practice in the air separation industry involves the use of linear dynamic models and linear model predictive control. This approach has proven adequate because production rates are changed infrequently and startups/shutdowns are uncommon.

Deregulation of the electric utility industry is expected to lead to frequent and unpredictable changes in the cost of electricity. This will dictate fundamental changes in the operating philosophy of air separation plants. Large changes in production rate and more frequent startups/shutdowns will be required to take full advantage of timevarying utility rates. Process nonlinearities will become much more pronounced under these conditions, and some type of non-linear control will be required to achieve satisfactory operation. The availability of a suitable nonlinear dynamic model is prerequisite for the development of a nonlinear model-based control strategy. Since a typical nitrogen purification column has approximately 40 theoretical stages, a rigorous nonlinear model comprised of mass and energy balances for each stage is too complex for on-line control applications.

A number of researchers have investigated the formulation of low-order distillation column models and the use of these models for controller design [3,4,13]. Benallou et al. [3] achieves order reduction by combining a number of stages into a single equivalent stage. Levine and Rouchon [13] propose a similar approach based on singular perturbation techniques [12] to generate a reduced-order model that accounts only for slow column dynamics. Gilles and Retzbach [4] propose a low-order dynamic model for distillation columns with sharp temperature profiles based on 
nonlinear wave theory and utilize the model for temperature profile position control.

Nonlinear wave theory was developed originally for multicomponent chromatography [7,21]. The propagation of temperature and composition profiles in high-purity distillation columns was studied by Luyben [14]. Later Marquardt [15] derived expressions for the wave propagation velocity and the shape of the wave profile in distillation columns from differential material balances. Meanwhile, Hwang and Helfferich [8,10] developed a distributed wave model for general counterflow separation processes. The model was used to capture the propagation, reflection, superposition and self-sharpening behaviors of concentration waves in nonlinear distillation columns [9]. More recently, a number of papers illustrating the use of wave models for distillation column control have appeared $[1,2,5,6,19]$.

In this paper, a low-order wave model for a nitrogen purification column is derived and compared with a first-principles model developed within the commercial dynamic simulator HYSYS.Plant (Hyprotech). As compared with the earlier work on nonlinear wave modeling of distillation columns, the major contributions of this paper include the application of wave modeling to cryogenic air separation columns, rigorous modeling of the combined reboiler/condenser assembly and the use of a rigorous dynamic simulator for model verification. The remainder of the paper is organized in four sections. Section 2 provides a brief review of nonlinear wave theory for distillation column modeling. In Section 3, the HYSYS simulator is briefly described and the low-order wave model is developed. The low-order model is compared with the HYSYS simulator in Section 4. Section 5 concludes the paper with a discussion of potential modeling enhancements and future control applications.

\section{Nonlinear wave models for distillation columns}

The basic idea of the nonlinear wave modeling approach is that the concentration or temperature profile of a distillation column can be described as a wavefront with constant shape. Column distur- bances such as feed concentration and flow rate changes result in the movement and distortion of this profile. A number of assumptions are necessary to formulate simple mathematical expressions for the wave phenomenon. This allows the nonlinear wave model to be derived from differential material balances and equilibrium relations that characterize the wave profile and velocity. Wave models for distillation columns are typically based on the following assumptions:

1. Constant molar overflow.

2. Constant molar holdup.

3. Constant relative volatility.

4. Perfect tray efficiency.

5. Binary mixture.

6. Constant wave pattern.

In the following section the validity of the first five assumptions is evaluated using the HYSYS simulator. The constant wave pattern assumption is unique to nonlinear wave models. It is necessary to achieve the desired order reduction and works well for highly pinched separations in which the composition profile is flat at both ends of the column. As shown later, the determination of an appropriate wave pattern is critical for generating accurate predictions. Later the potential limitation of this critical assumption is evaluated.

A nonlinear wave is defined in mathematical physics as a structure moving along a spatial coordinate with constant propagation velocity and constant shape. The high-order dynamics of distillation columns can be approximated by modeling the composition and temperature profiles as traveling nonlinear waves. To obtain the concentration profile and wavefront velocity equations, we start from the following differential material balances for a packed column [15]:

$\frac{\partial x}{\partial \tau}-\frac{\partial x}{\partial z}=-B\left(y^{*}-y\right)$

$\frac{n_{\mathrm{v}}}{n_{1}} \frac{\partial y}{\partial \tau}+\frac{V}{L} \frac{\partial y}{\partial z}=B\left(y^{*}-y\right)$

where $y$ and $x$ are vapor and liquid compositions, respectively; $y^{*}$ is the vapor composition in equilibrium with $x ; n_{\mathrm{v}}$ and $n_{1}$ are the vapor and liquid holdups on each tray, respectively; $V$ and $L$ are 
vapor and liquid molar flow rates, respectively; $B$ is a dimensionless mass transfer coefficient; and $\tau$ and $z$ are the dimensionless time and spatial coordinates, respectively. The composition profile can be derived from these differential material balances if the vapor-liqiud equilibrium relation $y^{*}=f(x)$ is known $[11,15]$. The wavefront propagation velocity can be derived from an overall material balance [16] or a material balance across the discontinuous shock wave front [21].

By assuming local equilibrium, $y=y^{*}=f(x)$, the propagation velocity of a specific concentration $x_{i}$ can be derived from Eqs. (1) and (2) [10]:

$$
\left(\frac{\mathrm{d} z}{\mathrm{~d} \tau}\right)_{x_{i}}=\frac{-1+(V / L)[\mathrm{d} y / \mathrm{d} x]_{x_{i}}}{1+\left(n_{\mathrm{v}} / n_{1}\right)[\mathrm{d} y / \mathrm{d} x]_{x_{i}}}
$$

It has been shown [21] that the wave is self-sharpening and will result in a discontinuity (shock wave formation) if the equilibrium relationship satisfies $\mathrm{d}^{2} y / \mathrm{d} x^{2}<0$. In practice, there always is a finite mass transfer rate and boundary effects also will counteract the self-sharpening tendency of the wave [10]. Therefore, a constant pattern wave is observed instead of a shock wave.

Nevertheless, the wave propagation velocity can be approximated as the velocity of the idealized shock wave. The shock wave velocity equation can be derived using a component balance from the standpoint of an observer on the discontinuity [21] or from an overall component balance on the column with a discontinuous composition profile [16]. The velocity $(w)$ expressed in actual time and normalized column height is:

$w=\frac{1}{N} \frac{-L\left(x_{\text {in }}-x_{\text {out }}\right)+V\left(y_{\text {out }}-y_{\text {in }}\right)}{n_{1}\left(x_{\text {in }}-x_{\text {out }}\right)+n_{\mathrm{v}}\left(y_{\text {out }}-y_{\text {in }}\right)}$

where $N$ is the total number of theoretical stages; $x_{\text {in }}$ and $x_{\text {out }}$ are the liquid compositions entering and exiting the column, respectively; and $y_{\text {in }}$ and $y_{\text {out }}$ are the vapor compositions entering and exiting the column, respectively. Two distinct wave fronts with different wave velocities exist in the rectifying and stripping sections when the feed enters the middle of the column. For the nitrogen column, there only is a rectifying section since the feed enters the bottom of the column. Marquardt and Amrhein [16] have derived an expression for the wave front velocity when the concentration profile has varying shape. They note that the effect of varying shape on the wave velocity is small.

The derivation of the composition profile for binary columns is attributable to Marquardt [15]. The wave coordinates $\xi$ is formally defined as:

$\xi=z-v t$

Then the material balances Eqs. (1) and (2) take the form:

$-(1+w) \frac{\mathrm{d} x}{\mathrm{~d} \xi}=-B\left(y^{*}-y\right)$

$\left(-\frac{n_{\mathrm{v}}}{n_{1}} w+\frac{V}{L}\right) \frac{\mathrm{d} y}{\mathrm{~d} \xi}=B\left(y^{*}-y\right)$

The composition profile expression can be derived from Eqs. (6) and (7) given the equilibrium relation $y=f(x)$. For a quadratic equilibrium relation, the composition can be expressed explicitly in terms of the spatial position along the column:

$y(z)=y_{\min }+\frac{y_{\max }-y_{\min }}{1+\exp [-\gamma(z-s)]}$

where $y_{\min }$ and $y_{\max }$ are the composition values as $z \rightarrow-\infty$ and $z \rightarrow+\infty$, respectively; $\gamma$ is the maximum slope of the profile; and $s$ is the location of the wave front. The column dynamics are predicted by tracking the wave position $s$ using the velocity Eq. (4). When an equilibrium relation with a constant volatility $\alpha$ is used:

$y^{*}(x)=\frac{\alpha x}{1+(\alpha-1) x}$

only an implicit solution to Eqs. (6) and (7) can be found [15]. In a recent paper by Kienle [11], the composition profile Eq. (8) is derived from this implicit solution under certain additional assumptions. Despite these limitations, the expression Eq. (8) is used in most nonlinear wave models due to its simplicity and the physical significance of its parameters.

In this paper, the wave parameters $y_{\min }, y_{\max }$ and $\gamma$ are estimated from steady-state composition profile data and are assumed to be constant in the subsequent dynamic simulations. Due to boundary effects on the wave profile, the wave parameters actually are time varying. This behav- 
ior becomes quite pronounced for columns that are not highly pinched [15]. To account this timevarying behavior, multiple points on the composition profile can be tracked to describe different velocities along spatial coordinate. This is accomplished by discretizing the profile with respect to the spatial coordinate [10]. However, a large number of ordinary differential equations are generated and resulting model is rather complex. Balasubramhanya and Doyle [1] propose the use of a Kalman filter for on-line estimation of the parameter $\gamma$. Their simulation results show close agreement between the adapted wave model and a detailed simulation model. We intend to utilize such an on-line parameter estimation scheme in our future closed-loop simulation studies. However, in this paper an estimator is not used to allow possible deficiencies of the nonlinear wave modeling approach to be investigated.

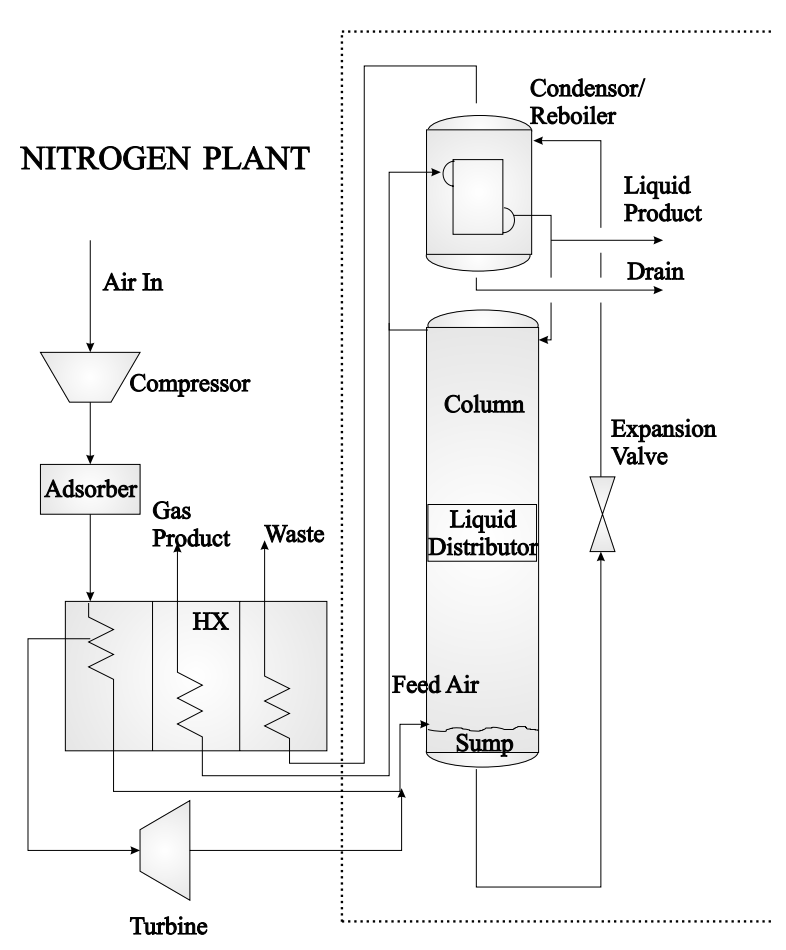

Fig. 1. Nitrogen plant process diagram.

\section{Low-order dynamic model for nitrogen plants}

The major process equipment for the nitrogen production plant is shown schematically in Fig. 1. The feed air stream is first compressed to a pressure of 4-8 bars. Impurities such as water and carbon dioxide are removed from the feed stream via adsorption. The purified air stream is cooled by waste and product streams from the column in a multi-pass heat exchanger. A portion of the feed stream is expanded to provide additional cooling. The combined feed stream is fed to the bottom of a distillation column with 42 theoretical stages. There is a sump below the feed stage where the bottom liquid is accumulated. The liquid distributor improves the flow characteristics of the liquid moving down the column. The bottom liquid stream is expanded through a valve and is partially liquefied. The resulting two-phase stream has a lower temperature than the overhead stream. In the combined condenser/reboiler, the partially liquefied bottom stream is vaporized and the gaseous nitrogen stream is condensed to produce the reflux stream and the liquid nitrogen product stream. Part of the column overhead stream is withdrawn as the high-purity gaseous nitrogen product. Since the main focus of this paper is cryogenic column modeling, only the equipment inside the dashed line in Fig. 1 are modeled. This includes the cryogenic column, the combined condenser/reboiler and the expansion valve.

\subsection{Rigorous nitrogen plant simulator}

The commercial software package HYSYS.Plant (Hyprotech) is used to develop a rigorous dynamic simulation of the nitrogen plant equipment inside the dashed line in Fig. 1. Equipment specifications and operating conditions correspond to a typical Praxair nitrogen plant. The rigorous simulator is used as the basis for evaluating predictions of the low-order wave model developed in the subsequent sections.

As a first step, the simulator is utilized to validate the assumptions upon which the wave model is based. The constant molar overflow and holdup assumptions are used to simplify the wave 
velocity equation. The implication of the constant molar overflow assumption is that the heat of vaporization of the mixture does not change with composition. This holds approximately if the components have similar heats of vaporization. The HYSYS simulator shows that the top stage vapor and liquid flow rates are only about $10 \%$ larger than the bottom flow rates due to heat of vaporization differences between pure nitrogen (1336 cal $/ \mathrm{mol})$ and pure oxygen $(1629 \mathrm{cal} / \mathrm{mol})$ [18]. The molar holdup is related to the column pressure and the molar volume of the mixture. In the simulator the vapor phase holdups are approximately constant along the column, but the top stage liquid phase holdup is about $15 \%$ smaller than that of the bottom stage. Consequently, the liquid molar holdup is assumed to be the average value over all stages. The constant relative volatility assumption is needed to derive the composition profile expression. In the simulator the relative volatility between nitrogen and oxygen varies from 2.97 at the bottom of the column to 2.74 at the top of the column. Instead of calculating the composition profile parameters from the relative volatility and mass transfer coefficient [11], these parameters are estimated from simulator steady-state data as shown in Section 5. The assumption of perfect tray efficiency often is invoked in distillation modeling and is also used in the HYSYS simulator. By considering oxygen and argon as a single lumped component, the problem is reduced to separation of a binary nitrogen/oxygen mixture. This assumption will be relaxed in our future work on triple column plants.

\subsection{Reduced-order column modeling}

The first step in formulating the nonlinear wave model is to find the parameters $y_{\max }, y_{\min }$, and $\gamma$ associated with the composition profile Eq. (8). These parameters are generated from steady-state composition profile data from the rigorous simulator by nonlinear least-squares estimation:

$\min _{y_{\min }, y_{\max }, \gamma_{i}=1} \sum_{i}^{N}\left[\hat{y}\left(z_{i}\right)-y\left(z_{i}\right)\right]^{2}$

subject to:

$$
\begin{aligned}
& \hat{y}\left(x_{1}\right)=y\left(z_{1}\right) \\
& \hat{y}\left(z_{N}\right)=y\left(z_{N}\right) \\
& 0 \leq y_{\max } \leq 1 \\
& 0 \leq y_{\min } \leq 1
\end{aligned}
$$

where $z_{i}$ is the normalized distance of stage $i$ from the bottom of the column; $\hat{y}\left(z_{i}\right)$ denotes the steady-state vapor phase composition estimate at stage $i$ obtained from Eq. (8); and $y\left(z_{i}\right)$ is the steady-state vapor phase composition at stage $i$ obtained from the simulator. Note that the column section includes all the theoretical stages above the feed. The boundary conditions guarantee that both models have the same concentrations at the column entrance and exit. The lower and upper limits maintain $y_{\min }$ and $y_{\max }$ within a physically meaningful region. The parameter estimation problem is solved using the constrained nonlinear optimization code fmincon available in the MATLAB Optimization Toolbox. While there is no guarantee that the code will converge to the global optimum, we found that the same solution is obtained for a rather large set of initial parameter values. On the other hand, it will be shown later that the parameter values obtained are strongly affected by the steady-state profile used for estimation.

The model equations shown include the nonlinear wave description of the column dynamics and a steady-state material balance for the feed stage. The steady-state approximation is justified because the feed stage dynamics are much faster than the overall column dynamics.

$$
\begin{aligned}
& w=\frac{\mathrm{d} s}{\mathrm{~d} t}=\frac{1}{N} \frac{-L\left(x_{\text {in }}-x_{\text {out }}\right)+q F\left(y_{\text {out }}-y_{\text {in }}\right)}{n_{1}\left(x_{\text {in }}-x_{\text {out }}\right)+n_{\mathrm{v}}\left(y_{\text {out }}-y_{\text {in }}\right)} \\
& y_{\text {out }}=y_{\text {min }}+\frac{y_{\text {max }}-y_{\text {min }}}{1+\exp [-\gamma(1-s)]} \\
& y(0)=y_{\text {min }}+\frac{y_{\text {max }}-y_{\text {min }}}{1+\exp (\gamma s)} \\
& x_{\text {out }}=\frac{y(0)}{\alpha-(\alpha-1) y(0)} \\
& y_{\text {in }}=\frac{\alpha x_{\mathrm{f}}}{1+(\alpha-1) x_{\mathrm{f}}} \\
& F z_{\mathrm{f}}+L x_{\text {out }}=q F y_{\text {in }}+[(1-q) F+L] x_{\mathrm{f}}
\end{aligned}
$$


where $F, q$ and $z_{\mathrm{f}}$ are the flow rate, vapor fraction and nitrogen composition of the feed air, respectively; and $x_{\mathrm{f}}$ is the feed stage liquid nitrogen composition. The wave front position $s$ is described by the velocity Eq. (11), which is identical to Eq. (4). Note that the liquid distributor holdup is split equally among all the stages to account for its dynamic effect. The composition of the overhead vapor stream $\left(y_{\text {out }}\right)$ is calculated from the composition profile Eq. (8) at the top of the column $(z=1)$. The vapor composition at the bottom of the column $(z=0)$ is calculated analogously. The composition of the existing liquid stream $\left(x_{\text {out }}\right)$ is determined from Eq. (9) based on the assumption that $x_{\text {out }}$ and $y(0)$ are equilibrium concentrations. The composition of the vapor stream entering the column $\left(y_{\text {in }}\right)$ is determined from Eqs. (15) and (16) where the feed stage is assumed to be in equilibrium and at steady state. The reflux stream composition $\left(x_{\text {in }}\right)$ is calculated from the condenser balances presented below. The Eqs. (15) and (16) involving $y_{\text {in }}$ and $x_{\mathrm{f}}$ can be combined to yield a single quadratic equation that can be solved for $x_{\mathrm{f}}$. It can be shown that one root always violates the constraint $0 \leq x_{\mathrm{f}} \leq 1$. The $y_{\text {in }}$ value corresponding to $x_{\mathrm{f}}$ can be substituted into the velocity Eq. (11). The vapor composition at each stage can be found from the profile Eq. (8), while the corresponding liquid compositions can be determined from the equilibrium relation Eq. (9). Therefore, the model Eqs. (11)-(16) can be reduced to a single nonlinear ordinary differential equation.

The top stage column pressure is equal to the condenser pressure, which is determined from the condenser model presented below. The column pressure profile is specified by assuming a constant, linear pressure drop between the top and bottom of the column. Since the composition and pressure of each stage are known, the stage temperatures can be determined from the vapor-liquid equilibrium relationship. For example, the feed stage temperature $T_{\mathrm{f}}$ can be calculated from Raoult's law since the solution is ideal and the pressure is moderate:

$$
y_{\text {in }} P_{\mathrm{f}}=x_{\mathrm{f}} P_{\mathrm{N}_{2}}^{\mathrm{sat}}\left(T_{\mathrm{f}}\right)
$$

where $P_{\mathrm{f}}$ is the feed stage pressure and $P_{\mathrm{N}_{2}}^{\text {sat }}\left(T_{\mathrm{f}}\right)$ is the nitrogen vapor pressure estimated from Wagner's equation [20].

\subsection{Dynamic modeling of the associated equipment}

Dynamic model equations for the columns sump, the expansion valve and the combined condenser/reboiler are required to predict the overhead pressure and reflux composition. The composition of liquid in the column sump is assumed to be equal to feed stage liquid composition $\left(x_{\mathrm{f}}\right)$ for simplicity. The sump level is described by the following material balance equation:

$\frac{\mathrm{d} H_{\mathrm{s}}}{\mathrm{d} t}=\frac{1}{\rho\left(x_{\mathrm{f}}\right) V_{\mathrm{s}}}\left[L+(1-q) F-F_{\mathrm{s}}\right]$

where $H_{\mathrm{s}}, V_{\mathrm{s}}$ and $F_{\mathrm{s}}$ denote the sump level, sump volume and sump outflow, respectively. The sump outlet flow is manipulated by a proportional-integral (PI) controller that regulates the sump level. The density $\rho\left(x_{\mathrm{f}}\right)$ is estimated from the pure component density. Using a linear mixing rule:

$\rho\left(x_{\mathrm{f}}\right)=x_{\mathrm{f}} \rho_{\mathrm{N}_{2}}+\left(1-x_{\mathrm{f}}\right) \rho_{\mathrm{O}_{2}}$

The bottom stream temperature is reduced by expansion. Properties of the resulting two-phase stream are determined from a flash calculation across the expansion valve. The enthalpy calculation is performed at constant pressure because the reboiler pressure is regulated by a PI controller and should not vary significantly from its setpoint. Model equations for the expansion valve are listed in the Appendix A. After exiting the expansion valve, the bottom stream is fed to the reboiler. Expansion causes the bottom stream temperature to become lower than the temperature of the vapor exiting the top of the column. Therefore, the bottom stream inside the reboiler is used to condense the overhead vapor stream in the condenser. Fig. 2 depicts the operation of the combined condenser/reboiler. In the reboiler, a large amount of liquid is vaporized $\left(F_{\mathrm{V}}\right)$ and significant amount of the liquid $\left(F_{\mathrm{L}}\right)$ is carried away from the pool by the vaporizing stream. The liquid stream spills over the side of the condenser 


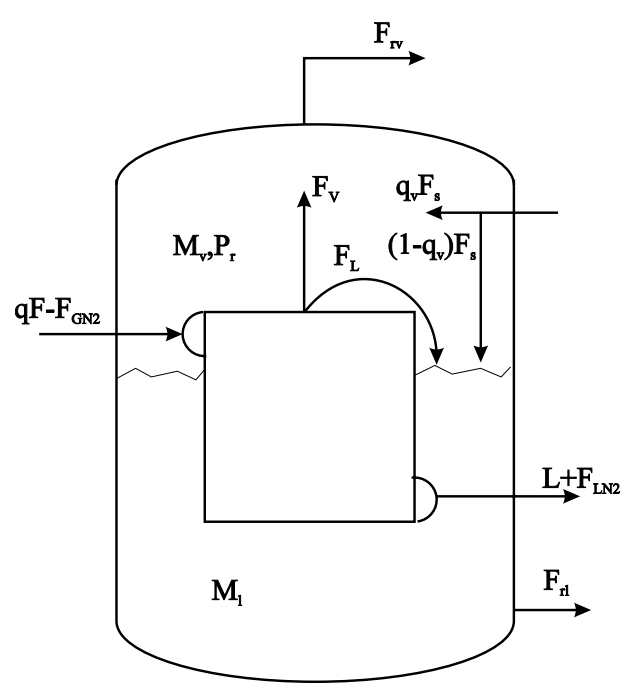

Fig. 2. Combined condenser/reboiler.

and then is returned to the liquid pool. Since the bulk of the reboiler liquid and vapor phases are not in direct contact, they cannot be assumed to be in equilibrium. However, the vaporizing stream and the returning liquid stream are in equilibrium. Therefore, the reboiler can be modeled by separate balances for each phase coupled with a flash calculation for the vaporizing stream.

Three assumptions are invoked for the combined condenser/reboiler to reduce the complexity of the resulting model. The first assumption is that the ratio of the reboiler-vaporizing stream flow rate $\left(F_{\mathrm{V}}\right)$ and returning liquid stream flow rate $\left(F_{\mathrm{L}}\right)$ is constant. This allows the reboiler temperature, the flow rates $F_{\mathrm{V}}$ and $F_{\mathrm{L}}$, and the associated compositions to be determined from a flash calculation and a liquid phase energy balance. The second assumption is that the temperature difference between reboiler and condenser is constant. This assumption eliminates the need for an additional condenser energy balance and is supported by plant data. The third assumption is that the condenser liquid is saturated. This allows the condenser pressure to be determined directly from the component vapor pressures and the liquid composition. The reboiler pressure and level are controlled by PI controllers, which manipulate the reboiler vapor and liquid exit flows, respec- tively. The resulting model equations for the reboiler are listed in the Appendix A.

The condenser temperature is approximated as $T_{\mathrm{c}}=T_{\mathrm{r}}+\Delta T$, where $\Delta T$ is a constant temperature difference between the reboiler and condenser. Since the condenser liquid is assumed to be saturated, the condenser pressure $P_{\mathrm{c}}$ is calculated as:

$P_{\mathrm{c}}=x_{\mathrm{c}} P_{\mathrm{N}_{2}}^{\mathrm{sat}}\left(T_{\mathrm{c}}\right)+\left(1-x_{\mathrm{c}}\right) P_{\mathrm{O}_{2}}^{\mathrm{sat}}\left(T_{\mathrm{c}}\right)$

where $x_{\mathrm{c}}$ is the condenser liquid composition. In the limit as the condenser liquid is pure nitrogen, this equation reduces to $P_{\mathrm{c}}=P_{\mathrm{N}_{2}}^{\mathrm{sat}}\left(T_{\mathrm{c}}\right)$. The condenser level $\left(H_{\mathrm{c}}\right)$ and liquid composition $\left(x_{\mathrm{c}}\right)$ are described by following mass balance equations:

$\frac{\mathrm{d} H_{\mathrm{c}}}{\mathrm{d} t}=\frac{q F-F_{\mathrm{LN}_{2}}-F_{\mathrm{GN}_{2}}-L}{\rho\left(x_{\mathrm{c}}\right) V_{\mathrm{c}}}$

$\frac{\mathrm{d} x_{\mathrm{c}}}{\mathrm{d} t}=\frac{\left(q F-F_{\mathrm{GN}_{2}}\right)\left(y_{\text {out }}-x_{\mathrm{c}}\right)}{\rho\left(x_{\mathrm{c}}\right) V_{\mathrm{c}} H_{\mathrm{c}}}$

where $V_{\mathrm{c}}$ is the condenser volume; and $F_{\mathrm{LN}_{2}}$ and $F_{\mathrm{GN}_{2}}$ are the liquid and gas nitrogen production rates, respectively.

The complete nitrogen column model is comprised of eight ordinary differential Eqs. (11), (18), (21) and (22), (A20)-(A23) and fifteen algebraic Eqs. (17) and (20), (A1)-(A6) and (A13)(A19). The majority of the equations are associated with the expansion valve and the combined condenser/reboiler. The dependent variables in the differential equations are $s, H_{\mathrm{s}}, H_{\mathrm{c}}, x_{\mathrm{c}}, H_{\mathrm{r}}$, $P_{\mathrm{r}}, x_{\mathrm{r}}$ and $y_{\mathrm{r}}$. The variables determined from the algebraic equations are $T_{\mathrm{f}}, P_{\mathrm{c}}, T_{\mathrm{v}}, y_{\mathrm{N}_{2}}^{\mathrm{v}}, y_{\mathrm{O}_{2}}^{\mathrm{v}}, x_{\mathrm{N}_{2}}^{\mathrm{v}}$, $x_{\mathrm{O}_{2}}^{\mathrm{v}}, q_{\mathrm{v}}, T_{\mathrm{r}}, y_{\mathrm{N}_{2}}^{\mathrm{r}}, y_{\mathrm{O}_{2}}^{\mathrm{r}}, x_{\mathrm{N}_{2}}^{\mathrm{r}}, x_{\mathrm{O}_{2}}^{\mathrm{r}}, F_{\mathrm{V}}$ and $F_{\mathrm{L}}$. The differential-algebraic equation model is solved in MATLAB using the variable step integration code ode45. In addition to the model equations described above, four PI control loops are included for regulation of the column sump level $\left(H_{\mathrm{s}}\right)$, reboiler level $\left(H_{\mathrm{r}}\right)$, reboiler pressure $\left(P_{\mathrm{r}}\right)$ and condenser level $\left(H_{\mathrm{c}}\right)$. The manipulated variables for these controllers are the sump exit flow $\left(F_{\mathrm{s}}\right)$, reboiler liquid exit flow $\left(F_{\mathrm{rl}}\right)$, reboiler vapor exit flow $\left(F_{\text {rv }}\right)$ and reflux rate $(L)$. The PI controllers are tuned to have similar closed-loop responses as those observed in the HYSYS simulator. Although both the simulator and the low-order model include an explicit control loop for the 
condenser level, this controller is not required in actual plants because the level is self-regulating.

\section{Simulation study}

Possible disturbances encountered during normal operation of a nitrogen plant include changes in the feed air rate, feed air vapor fraction, and the desired gaseous and liquid nitrogen production rates. The liquid and vapor flow rates inside the column will change transiently as a result of these disturbances. The composition profile will move up or down the column until a new steadystate position is established. Since we are interested in the dynamic behavior of the nitrogen column during startups and shutdowns, disturbances that cause large movements in the wavefront are considered. First a set of wave model parameters must be estimated from a representative steady-state composition profile.

\subsection{Parameter estimation using steady-state simulator data}

During normal operation, the cryogenic distillation column produces gaseous and liquid nitrogen products with 1 ppm oxygen and 1000 ppm argon. A steady state of the simulator correspond- ing to a high purity nitrogen product is listed in Table 1 as HYSYS SS1. Also shown in Table 1 is a steady-state corresponding to a lower product purity, which is referred to as HYSYS $S S 2$. The wave model parameters $\left(y_{\min }, y_{\max }, \gamma\right)$ are estimated for each HYSYS steady state by solving the optimizing problem (Eq. (10)). The results are:

- $S S 1, y_{\min }=0.7367 ; y_{\max }=1 ; \gamma=6.6154$.

- $S S 1, y_{\min }=0.7894 ; y_{\max }=1 ; \gamma=11.1578$.

Fig. 3 shows the vapor phase $\mathrm{N}_{2}$ composition along the column for the two HYSYS steady states and the low-order wave model. While the composition profile can be approximated accurately with the function Eq. (8), the optimal parameters $y_{\min }$ and $\gamma$ are different for the two steady states. The wave front slope $(\gamma)$ changes as the wave propagates through the column due to the boundary effects described earlier. Under the constant pattern assumption, the performance of the nonlinear wave model depends strongly on the steady-state profile used for estimation. It is important to note that the value of $y_{\min }$ should not change unless the feed composition changes. We have found that $S S 2$ yields a better estimate of $y_{\text {min }}$ because the bottom composition is very close to the pinched lower column composition. The steady state $S S 1$ yields a lower $y_{\text {min }}$ estimate than the true value because the nitrogen composition is not pinched at the column bottom. Although SS1

Table 1

Nitrogen plant steady-state operating conditions

\begin{tabular}{lllll}
\hline Variables & HYSYS $S S 1$ & Low-order $S S 1$ & HYSYS $S S 2$ & Low-order $S S 2$ \\
\hline$F(\mathrm{kmol} / \mathrm{h})$ & 100.8 & 100.8 & 98.5 & 98.5 \\
$q$ & 0.969 & 0.969 & 0.965 & 0.965 \\
$z_{\mathrm{f}}$ & 0.7811 & 0.7811 & 0.7811 & 0.7811 \\
$T_{\mathrm{f}}\left({ }^{\circ} \mathrm{C}\right)$ & -179.9 & -180.07 & -179.9 & -179.89 \\
$y_{\mathrm{ou} t}$ & 0.9990 & 0.9990 & 0.9956 & 0.9956 \\
$P_{\mathrm{top}}(\mathrm{kPa})$ & 326.8 & 327.9 & 326.8 & 329.3 \\
$H_{\mathrm{s}}(\%)$ & 50 & 50 & 50 & 50 \\
$T_{\mathrm{v}}\left({ }^{\circ} \mathrm{C}\right)$ & -189.0 & -189.16 & -188.9 & -189.15 \\
$q_{\mathrm{v}}$ & 0.09123 & 0.0923 & 0.09518 & 0.0933 \\
$H_{\mathrm{r}}(\%)$ & 50 & 50 & 50 & 50 \\
$P_{\mathrm{r}}(\mathrm{kPa})$ & 134.5 & 134.5 & 134.2 & 134.3 \\
$T_{\mathrm{r}}\left({ }^{\circ} \mathrm{C}\right)$ & -185.8 & -185.9 & -185.8 & -185.8 \\
$x_{\mathrm{r}}$ & 0.2558 & 0.4690 & 0.2496 & 0.4633 \\
$y_{\mathrm{r}}$ & 0.5672 & 0.6534 & 0.5602 & 0.6483 \\
$H_{\mathrm{c}}(\%)$ & 50 & 50 & 50 & 50
\end{tabular}




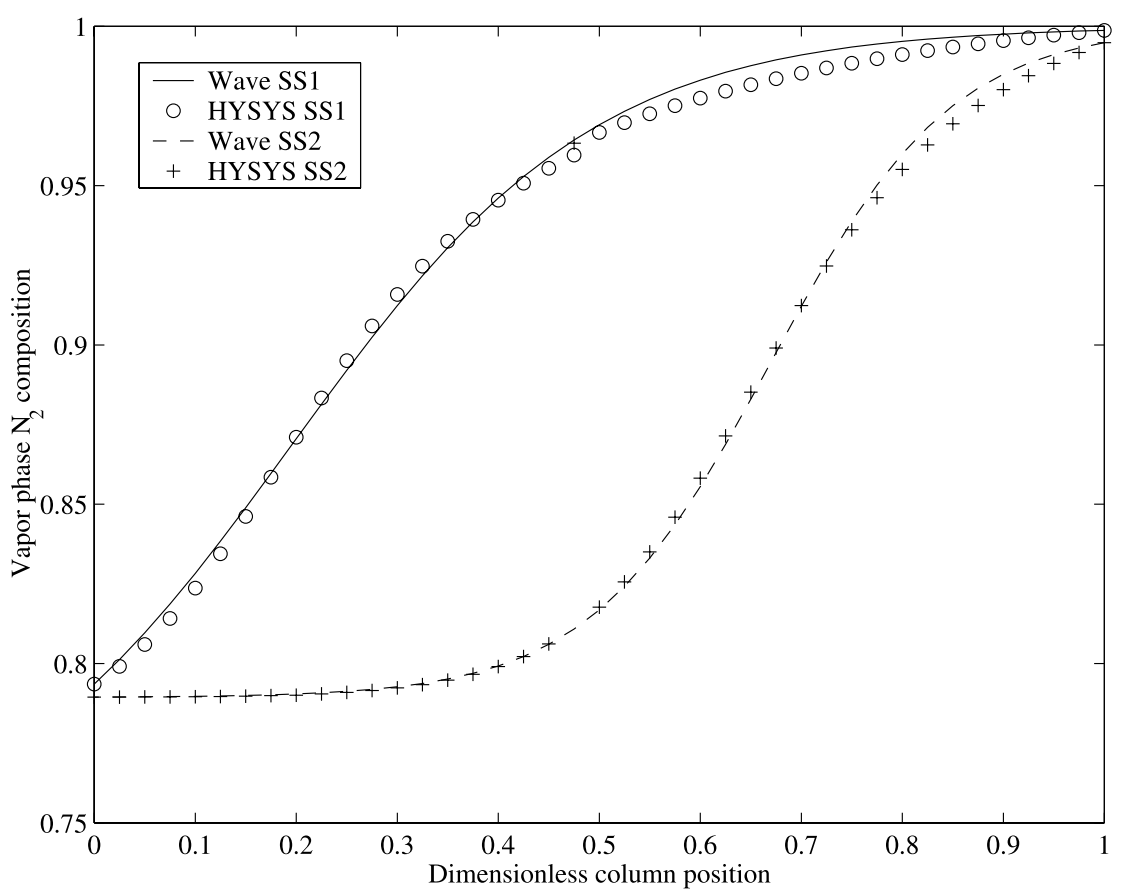

Fig. 3. Nonlinear wave model parameter estimation.

is the more desirable operating point, the parameters generated from $S S 2$ are preferred and used in the subsequent simulations.

The steady-state values generated from the HYSYS and wave models are compared in Table 1. The wave model predictions are in good agreement with the HYSYS steady states with the exception of the reboiler compositions $\left(x_{\mathrm{r}}\right.$ and $\left.y_{\mathrm{r}}\right)$. This discrepancy is a direct result of the simplified condenser/reboiler model. However, the streams exiting the reboiler are not products and they do not significantly affect the column dynamics. Since this paper focuses on column modeling, the simple condenser/reboiler model is considered adequate.

\subsection{Dynamic simulation results}

A number of tests involving step changes in the feed air rate are simulated using the HYSYS simulator and the low-order wave model developed in MATLAB. Disturbances in other variables such as feed vapor fraction and nitrogen production rates produce similar dynamic responses; therefore these results are not included.
Changes in feed composition generate different dynamic responses than do feed flow rate changes. However, such disturbances are not very meaningful for a single column air separation plant.

First the feed air rate is decreased by $10 \mathrm{kmol} / \mathrm{h}$ at $t=1 \mathrm{~h}$. The model responses are shown in Figs. 4 and 5. Fig. 4 shows the nitrogen vapor mole fraction in the top and bottom of the column. Both the HYSYS model (solid line) and the loworder wave model (dashed line) predict a decrease in the overhead composition $\left(y_{\text {out }}\right)$ since the reflux ratio decreases with lower reflux flow rate and constant product flow rates. However, the transient responses produced by two models are noticeably different. In particular, the wave model predicts faster $y_{\text {out }}$ dynamics than does the HYSYS model. Both models predict that the bottom composition $y(0)$ will decrease only slightly as the wave front moves upward in the column after the step change. Fig. 5 shows that the composition profile is pinched in the lower part of the column and the value of $y(0)$ is bounded below by $y_{\min }$.

The composition profiles at $t=1,1.2$ and $5 \mathrm{~h}$ shown in Fig. 5 illustrate the profile sharpening 
behavior of the HYSYS model. As explained earlier, this effect is attributable to the nonlinear equilibrium relationship, which causes the propagation velocity to decrease with increasing nitrogen concentration. The top composition $y_{\text {out }}$ initially is very close to unity and travels slower in the HYSYS model than it does in the nonlinear wave model where only the infection point of the wave front is tracked. In the HYSYS model $y_{\text {out }}$ decreases with an increasingly larger velocity until the wave approaches a new steady-state profile. By contrast, the constant wave pattern assumed in the derivation of the wave model requires that all concentrations travel with the same velocity. Although the two models produce very similar $y_{\text {out }}$ values at the new steady state, the shape of the composition profiles is significantly different.

To account for distortion of the wave shape, Balasubramhanya and Doyle [1] propose the use of a Kalman filter to update the wave parameter $\gamma$ based on measurements of the overhead and bottom compositions. Rehm and Allgower [19] directly calculate new values of $y_{\min }$ and $y_{\max }$ from the measured overhead compositions. To demonstrate the applicability of the wave model for on-line control applications, we show that at any instant $\gamma$ can be adjusted such that the wave model produces a very similar concentration profile to that the HYSYS model. Assuming the overhead composition is measured, the value of $\gamma$ at any time can be determined from the boundary condition $y(1)=y_{\text {out }}$ using the composition profile expression Eq. (8) with constant $y_{\min }$ and $y_{\max }$. In Fig. 6 the profiles generated from the updated $\gamma$ are compared with the HYSYS profiles from Fig. 5 at $t=1,1.2$ and $5 \mathrm{~h}$. The values calculated are $\gamma=11.16$ at $t=1 \mathrm{~h}, \gamma=14.37$ at $t=1.2 \mathrm{~h}$ and $\gamma=24.37$ at $t=5 \mathrm{~h}$. Clearly the use of a timevarying $\gamma$ allows much closer agreement with the HYSYS results. However, a constant $\gamma$ value is
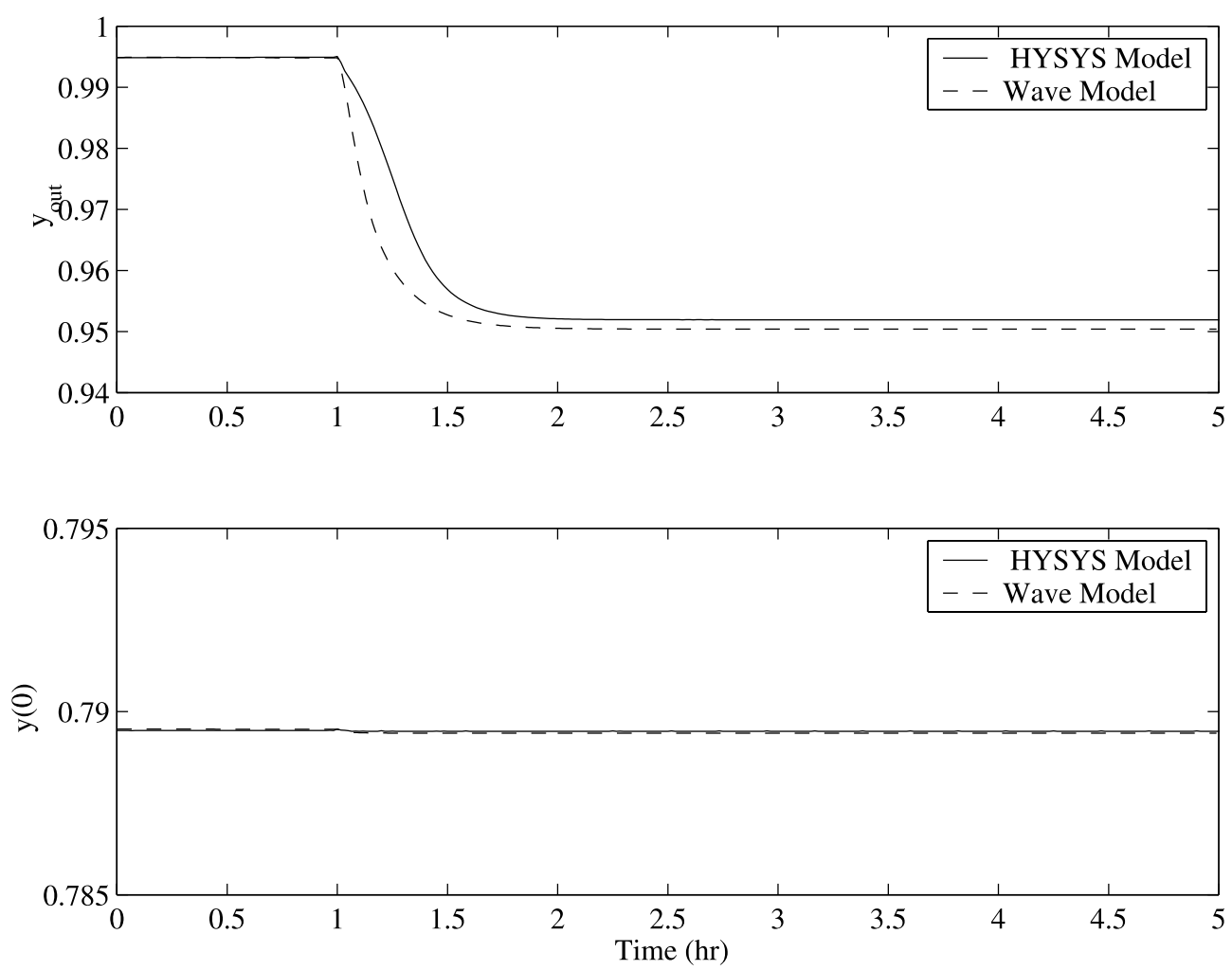

Fig. 4. $y_{\text {out }}$ and $y(0)$ responses for a $-10 \mathrm{kmol} / \mathrm{h}$ step change in the feed air flow rate $(S S 2)$. 


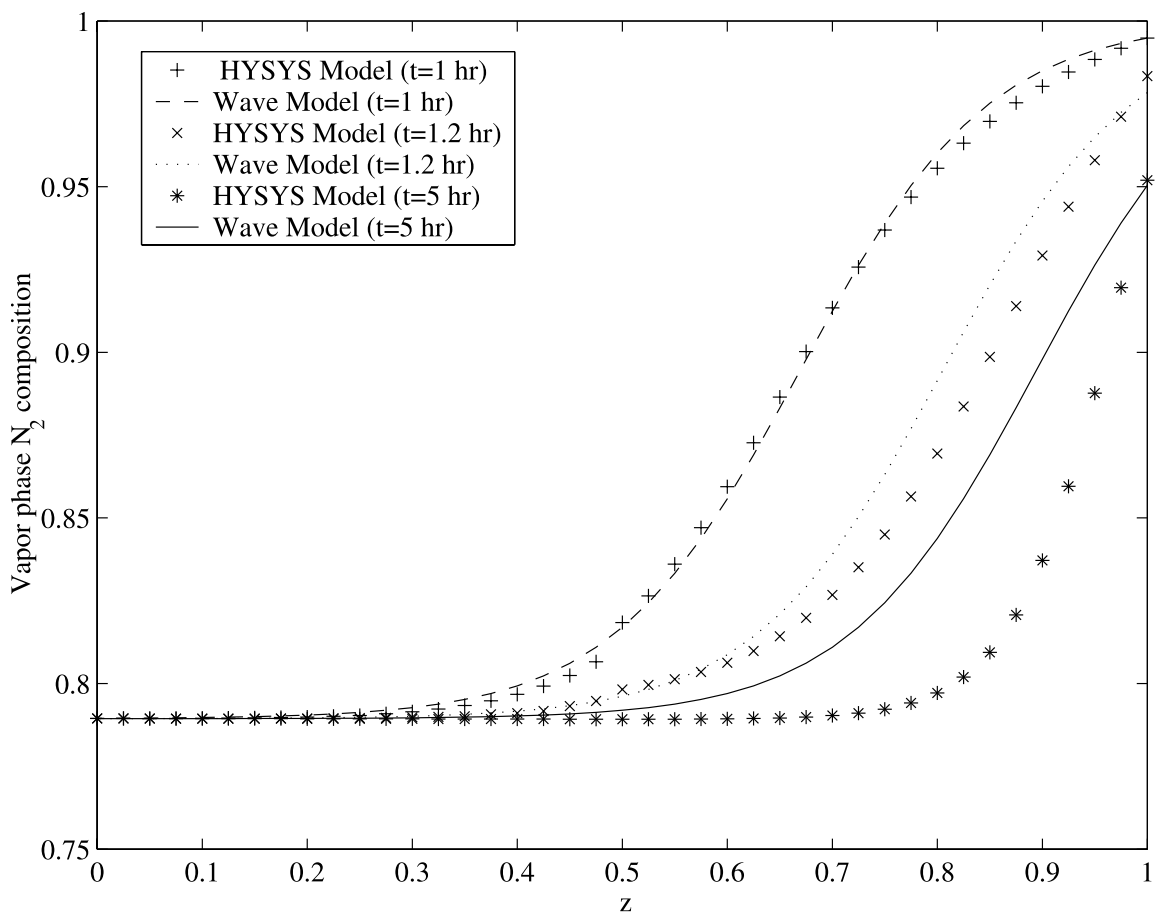

Fig. 5. Composition profile propagation corresponding to Fig. 4.

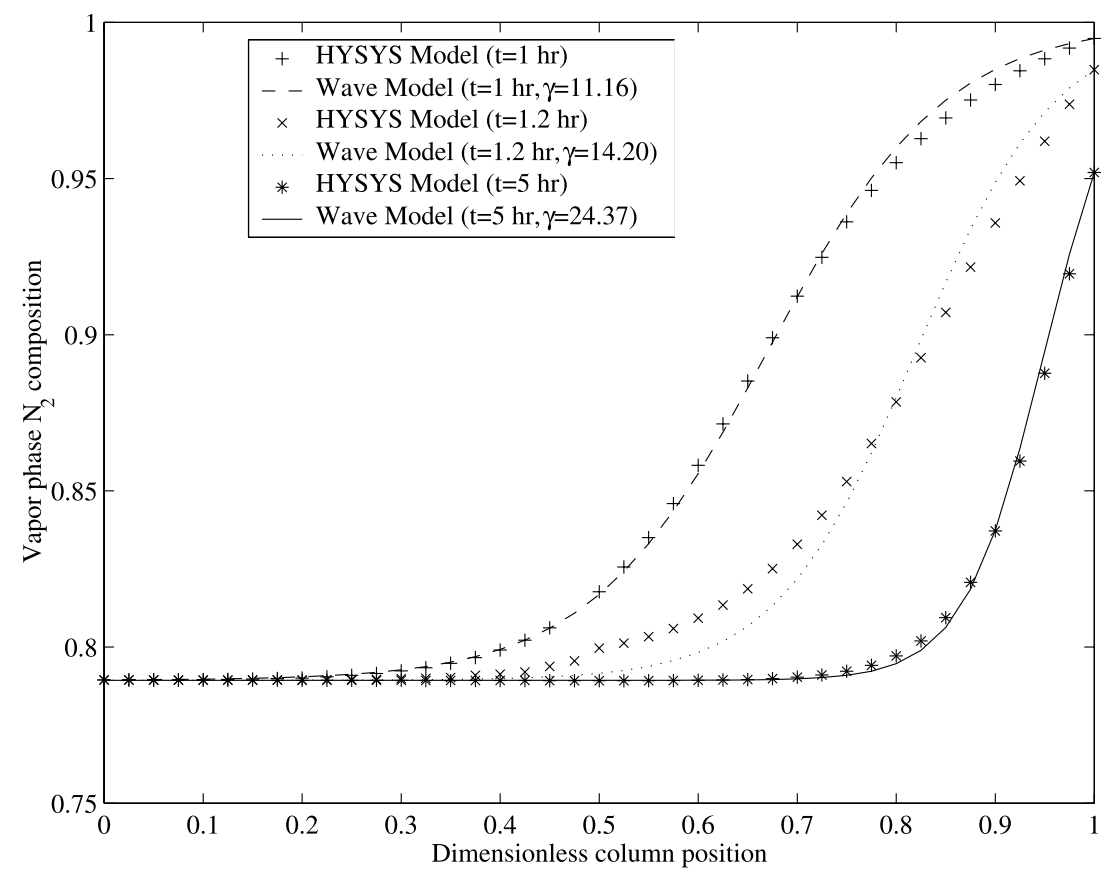

Fig. 6. Composition profile propagation with updated $\gamma$. 
used in the subsequent simulations to illustrate the behavior of the non-adapted wave model.

Fig. 7 shows the model responses obtained over a wide range of operating conditions when a series of small step changes $(-5 \mathrm{kmol} / \mathrm{h}$ at $t=1,4,7 \mathrm{~h}$ and $+5 \mathrm{kmol} / \mathrm{h}$ at $t=10,13 \mathrm{~h}$ ) in the feed air flow rate are introduced. For the first step change, a similar discrepancy between the model as in Fig. 4 is observed. However, the dynamic responses are in much closer agreement for the subsequent step changes. This occurs because the velocity difference between the inflection point tracked in the wave model and $y_{\text {out }}$ in the HYSYS model is reduced as the top composition moves away from the high purity region. This result supports the argument that the prediction error is caused primarily by the constant wave pattern assumption rather than the constant flow rate and holdup assumptions.

While the constant wave pattern assumption is required to achieve model order reduction, it does introduce some degree of modeling error since the actual plant exhibits more complex wave behavior. Now we show that the prediction accuracy of the nonlinear wave model depends strongly on the values of the wave parameters $\gamma, y_{\min }$ and $y_{\max }$. In Figs. 8 and 9, the wave model derived from the $S S 1$ profile is compared with the HYSYS model for a feed air flow rate change of $-10 \mathrm{kmol} / \mathrm{h}$ at $t=1 \mathrm{~h}$. The accuracy of the wave model is unacceptable for both the overhead and bottom compositions. The $y(0)$ response is particularly poor as the effect of the air flow rate change is grossly exaggerated. The high purity operating conditions at $S S 1$ yield an incorrect value for $y_{\min }$, which in turn causes the dramatic changes in $y(0)$. As demonstrated in Fig. 9, the estimated $y_{\min }$ value of 0.7367 causes the bottom composition to drop below the actual low limit.

Fig. 9 shows that the composition profile generated by the HYSYS model sharpens significantly as the wave travels up the column. The new steady-state value of the overhead composition is 0.963 while the wave model predicts a new steady-

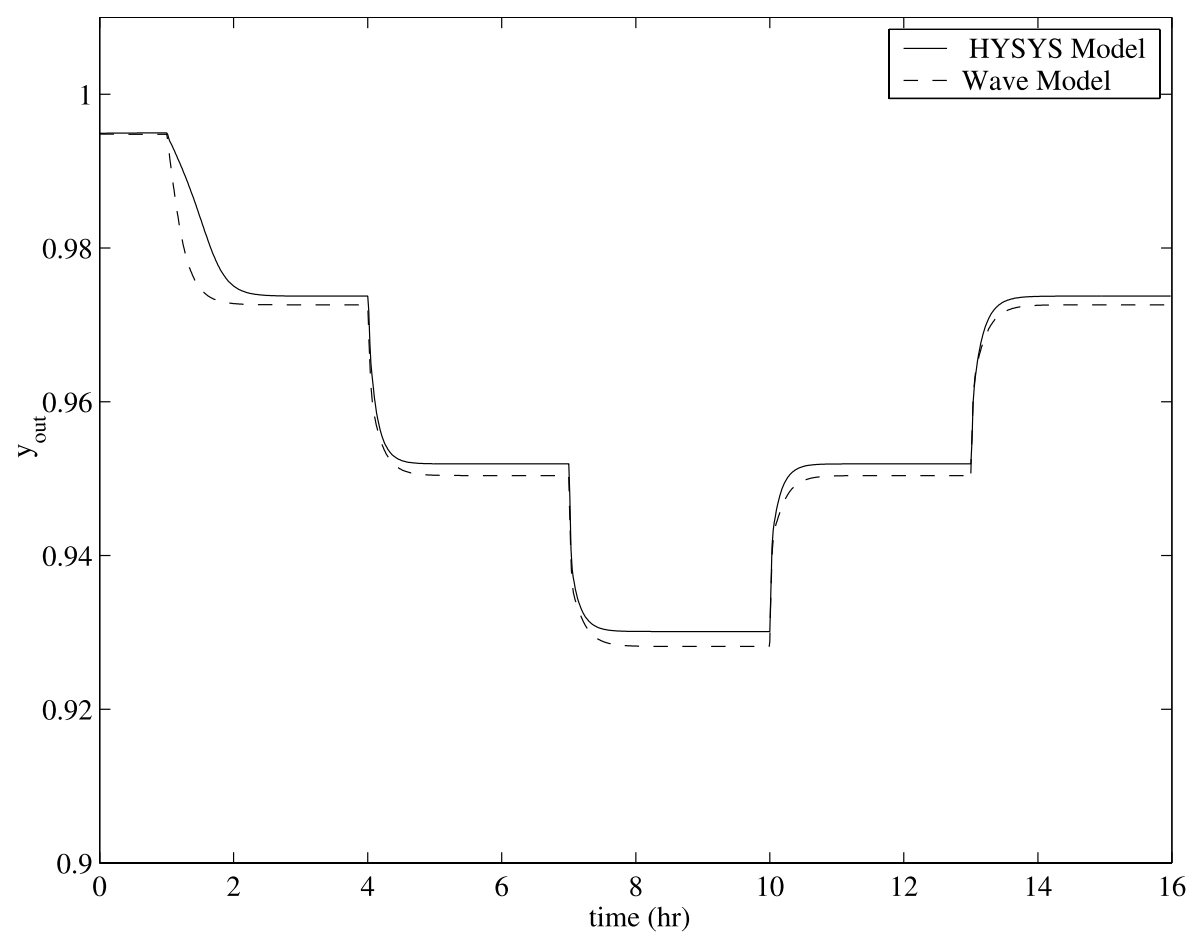

Fig. 7. $y_{\text {out }}$ response for multiple step change in the feed air flow rate $(S S 2)$. 

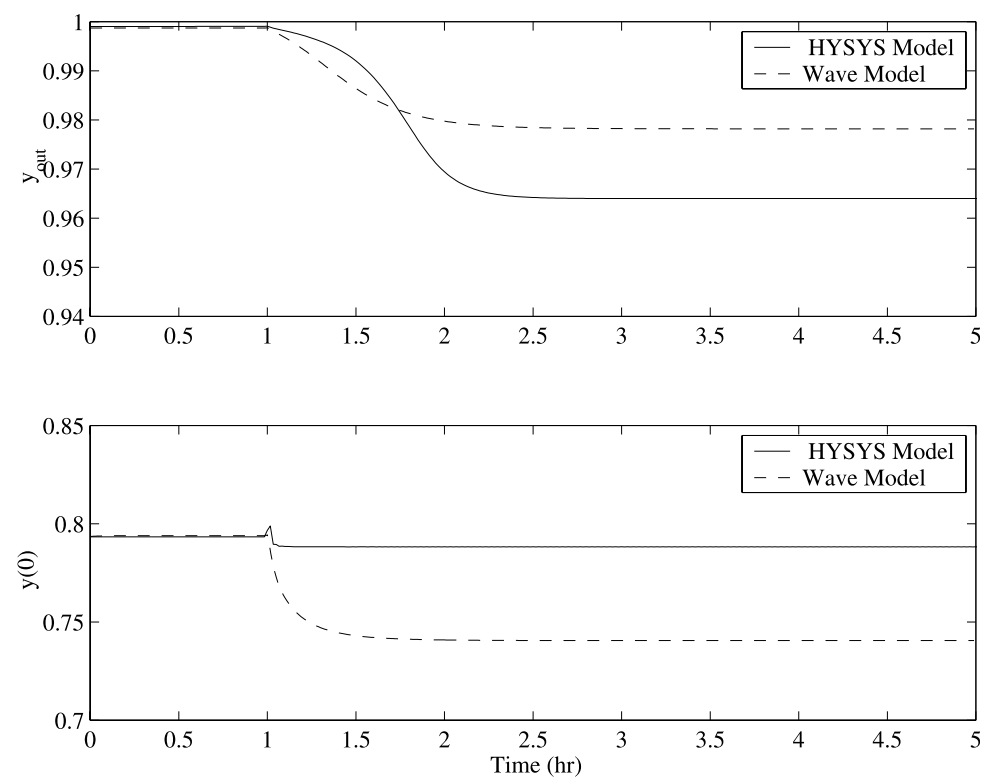

Fig. 8. $y_{\text {out }}$ and $y(0)$ response for a $-10 \mathrm{kmol} / \mathrm{h}$ step change in the feed air flow rate (SS1).

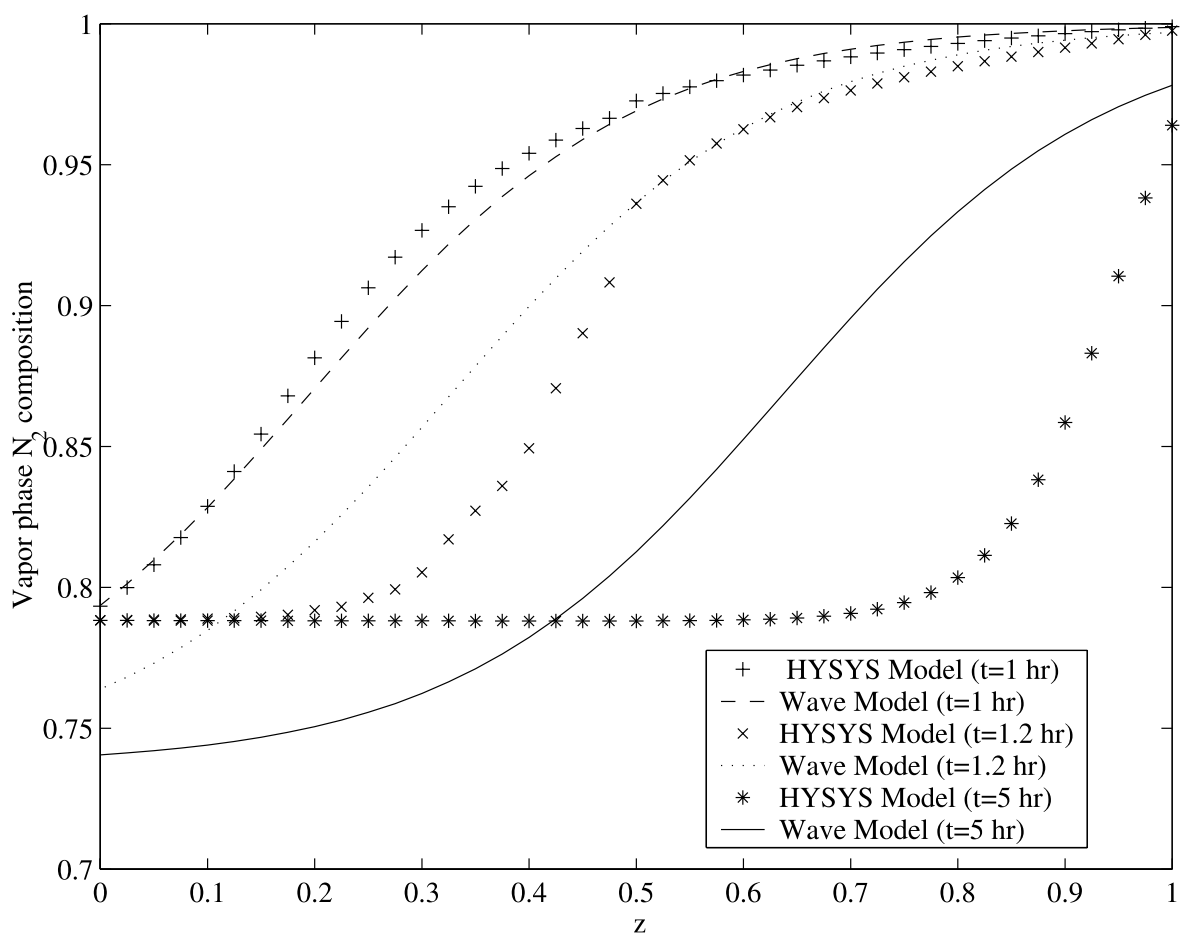

Fig. 9. Composition profile propagation corresponding to Fig. 8. 
state value of 0.978 . Note that the wave model predicts a smaller velocity for the overhead composition than does the HYSYS model. This can be explained through analysis of the steady-state profile $S S 1$ used for parameter estimation. For this steady-state compositions in the upper part of the column approach unity. When this profile is used for parameter estimation, poor estimates of the wave parameters are obtained and $y_{\text {out }}$ decreases slower than in the HYSYS model. As shown in Figs. 4 and 5, the prediction accuracy of the wave model is improved dramatically when a more representative wave profile is used to estimate the parameters.

Since the overhead products for $S S 1$ have very high purity, we are interested in modeling changes that lead to an ultra-high purity products. Figs. 10 and 11 show the results obtained when the feed air flow rate is increased by $4 \mathrm{kmol} / \mathrm{h}$ at $t=1 \mathrm{~h}$. As shown in Fig. 10, both models predict an increase in the top composition. The HYSYS model reaches a steady-state composition of 0.9996 while the wave model predicts a steadystate composition of 0.99997 . This difference probably is caused by small errors in the steady- state parameter estimation. A larger steady-state error is observed for the bottom composition. The initial and final steady-state composition profiles for the two models are shown in Fig. 11. The wave model yields slightly larger compositions near the top of the column than does the HYSYS model. This discrepancy leads to the observed difference in the overhead composition transient responses. The difference between the bottom compositions is more significant due to the constant wave pattern assumption used in the wave model. As the wave travels down the column, the velocity at a fixed composition decreases due to the nonlinear equilibrium relationship. Therefore, the HYSYS model bottom composition increases slower and converges to a smaller value.

When the plant is operated at ultra high purity, it is convenient to describe the top composition in terms of oxygen in parts per million (ppm). In this case, it is necessary to group the nitrogen and argon together and to formulate a wave model that describes the oxygen concentration profile. The formulation of the oxygen wave model is analogous to that presented earlier for nitrogen. Fig. 12 shows the response of the overhead oxy-
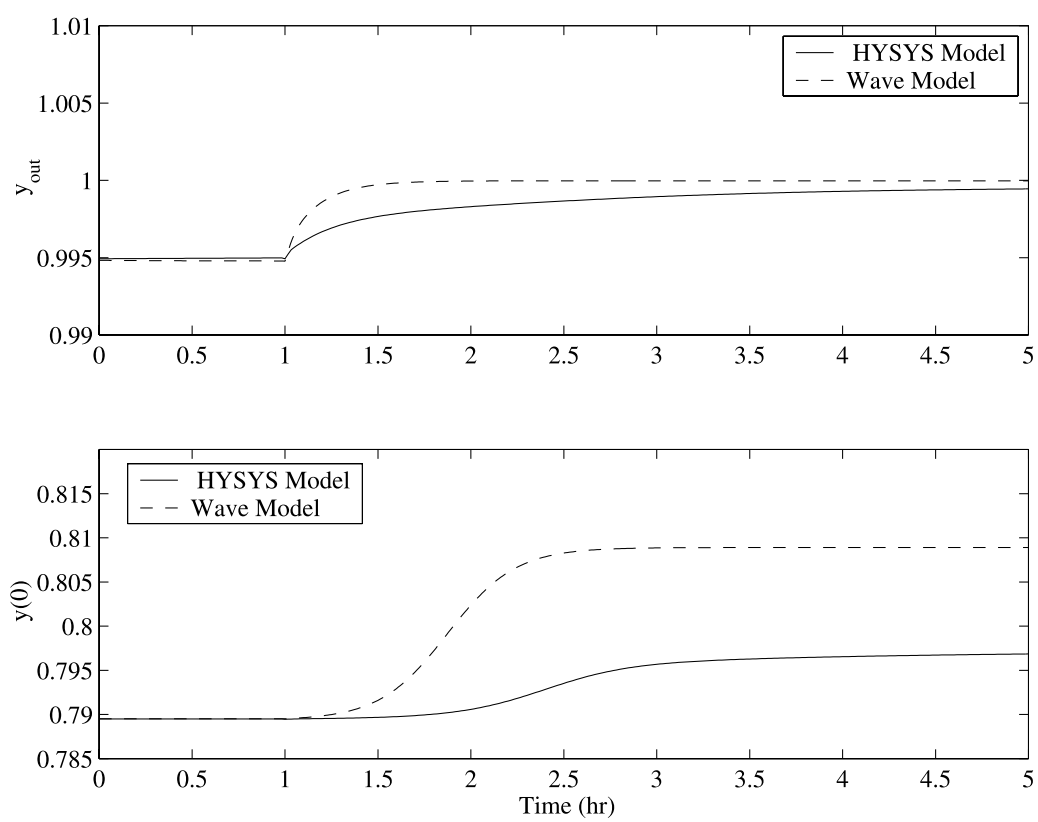

Fig. 10. $y_{\text {out }}$ and $y(0)$ response for $+4 \mathrm{kmol} / \mathrm{h}$ step change in the feed air flow rate $(S S 2)$. 


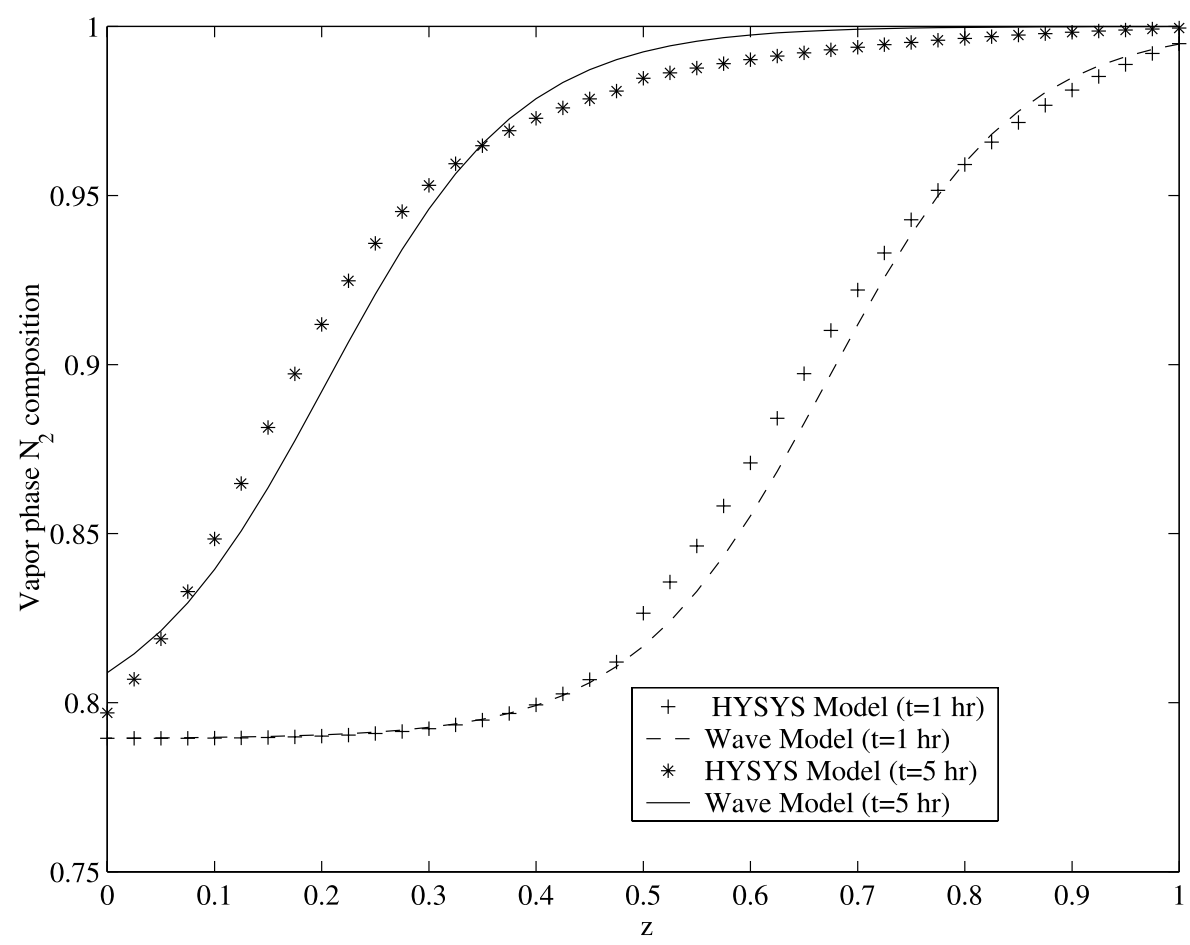

Fig. 11. Composition profile propagation corresponding to Fig. 10.

gen composition for a step change of $+2.4 \mathrm{~mol} / \mathrm{h}$ in the feed air flow rate. Although a small discrepancy in transient behavior is observed, the new steady-state value is close to that predicted by the HYSYS model. This occurs because the composition profile is very close to zero in the upper part of the column and a small distortion in the wave front does not significantly affect the overhead composition prediction. On the other hand, there is a more significant discrepancy between the bottom oxygen compositions due to profile distortion. These conclusions are supported by the composition profiles shown in Fig. 13.

\section{Discussion}

The nonlinear wave modeling approach has achieved significant order reduction for the single nitrogen column studied in this paper. A nitrogen column is designed to produce a high purity top product and has no purity requirement on the bottom stream. As a result, the wave profile parameters estimated from normal operating conditions are not suitable for model development. A small negative change in the air feed flow rate produces a more representative profile from which better parameter values can be obtained. Simulation results have shown that the low-order wave model is capable of producing acceptable prediction of composition responses for various types of disturbances. However, the constant wave pattern assumption used in the wave model development invariably leads to some degree of modeling error. We have shown that discrepancies between the nonlinear wave model and rigorous HYSYS simulator can be made acceptably small by adjustment of the wave slope $\gamma$.

In our future work, the nonlinear wave modeling approach will be applied to air separation plants with three columns that produce purified nitrogen, oxygen and argon. Each column section 
will require a separate wave model. A multicomponent wave model will be required for the ternary mixture in the upper column where all three components have significant concentrations. In a recent paper, Kienle [11] proposes linear superposition of nonlinear waves as a means to extend wave theory to multicomponent distillation columns. Our primary motivation for derivation of wave models is the development of a model-based nonlinear control strategy for air separation plants. We believe that it is feasible to solve the single column model comprised of eight ordinary differential equations and fifteen algebraic equations in an optimization-based framework such as nonlinear model predictive control [17]. The control work will be pursued in parallel with the nonlinear wave modeling work.

\section{Acknowledgements}

Financial support from Praxiar and the National Science Foundation (Grant CTS-9501368) is gratefully acknowledged.

\section{Appendix A}

\section{A.1. Expansion value model}

The model equations for the flash calculation are:

$$
\begin{aligned}
& y_{\mathrm{N}_{2}}^{\mathrm{v}} P_{\mathrm{r}}=P_{\mathrm{N}_{2}}^{\mathrm{sat}}\left(T_{\mathrm{v}}\right) x_{\mathrm{N}_{2}}^{\mathrm{v}} \\
& y_{\mathrm{O}_{2}}^{\mathrm{v}} P_{\mathrm{r}}=P_{\mathrm{O}_{2}}^{\mathrm{sat}}\left(T_{\mathrm{v}}\right) x_{\mathrm{O}_{2}}^{\mathrm{v}} \\
& x_{\mathrm{f}} F_{\mathrm{s}}=y_{\mathrm{N}_{2}}^{\mathrm{v}} F_{\mathrm{s}} q_{\mathrm{v}}-x_{\mathrm{N}_{2}}^{\mathrm{v}} F_{\mathrm{s}}\left(1-q_{\mathrm{v}}\right) \\
& \left(1-x_{\mathrm{f}}\right) F_{\mathrm{s}}=y_{\mathrm{O}_{2}}^{\mathrm{v}} F_{\mathrm{s}} q_{\mathrm{v}}-x_{\mathrm{O}_{2}}^{\mathrm{v}} F_{\mathrm{s}}\left(1-q_{\mathrm{v}}\right) \\
& x_{\mathrm{N}_{2}}^{\mathrm{v}}+x_{\mathrm{O}_{2}}^{\mathrm{v}}=1 \\
& h_{1}\left(T_{\mathrm{f}}, x_{\mathrm{f}}\right) F_{\mathrm{s}}=h_{1}\left(T_{\mathrm{v}}, x_{\mathrm{N}_{2}}^{\mathrm{v}}\right) F_{\mathrm{s}}\left(1-q_{\mathrm{v}}\right)+h_{\mathrm{v}}\left(T_{\mathrm{v}}, y_{\mathrm{N}_{2}}^{\mathrm{v}}\right) F_{\mathrm{s}} q_{\mathrm{v}}
\end{aligned}
$$

where the superscript/subscript $\mathrm{v}$ represents properties associated with the expansion valve exit stream; $y_{\mathrm{N}_{2}}^{\mathrm{v}}, x_{\mathrm{N}_{2}}^{\mathrm{v}}, y_{\mathrm{O}_{2}}^{\mathrm{v}}$ and $x_{\mathrm{O}_{2}}^{\mathrm{v}}$ are the vapor and liquid phase compositions of nitrogen and oxygen; $q_{\mathrm{v}}$ is the vapor fraction; $T_{\mathrm{v}}$ is the stream temperature; $P_{\mathrm{N}_{2}}^{\mathrm{sat}}$ and $P_{\mathrm{O}_{2}}^{\mathrm{sat}}$ are the nitrogen and oxygen vapor pressures, respectively; $h_{1}$ and $h_{\mathrm{v}}$ are liquid and vapor enthalpies, respectively; and the
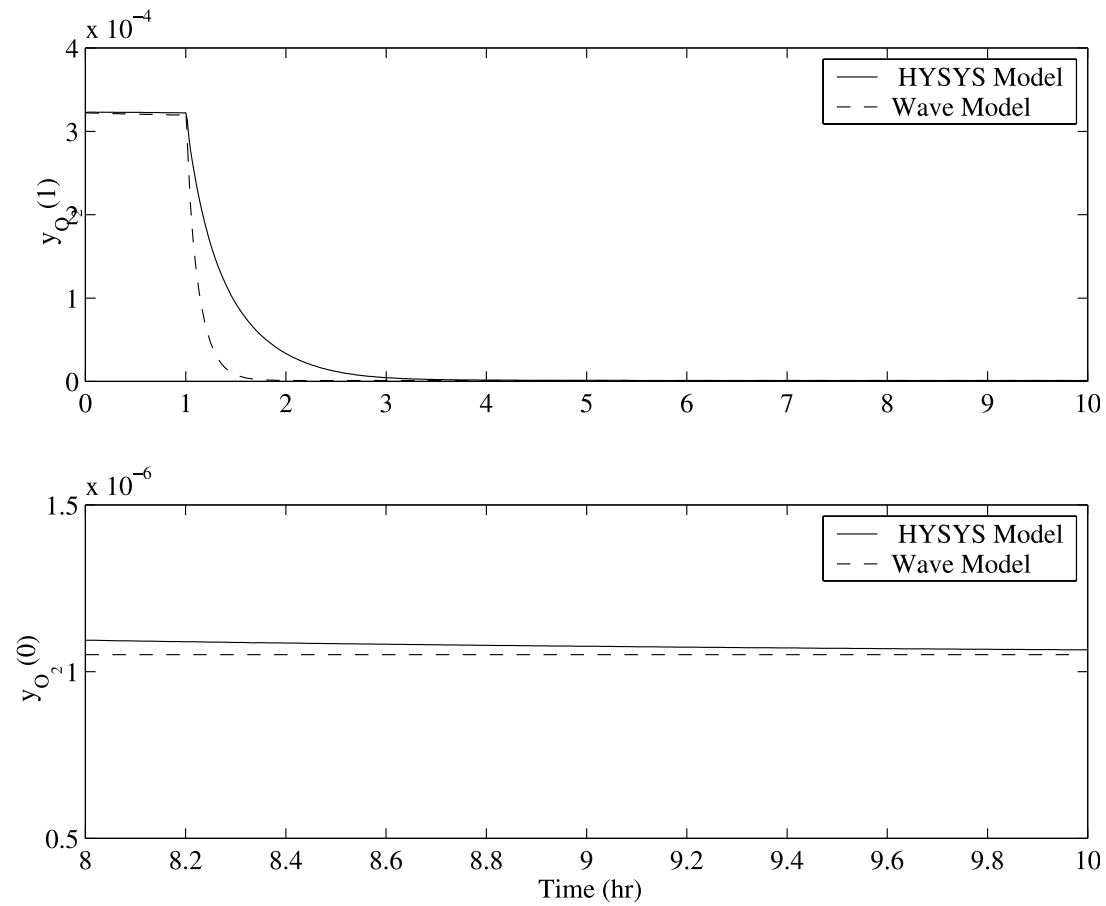

Fig. 12. Overhead oxygen composition responses for $+2.4 \mathrm{kmol} / \mathrm{h}$ step change in the feed air flow rate. 


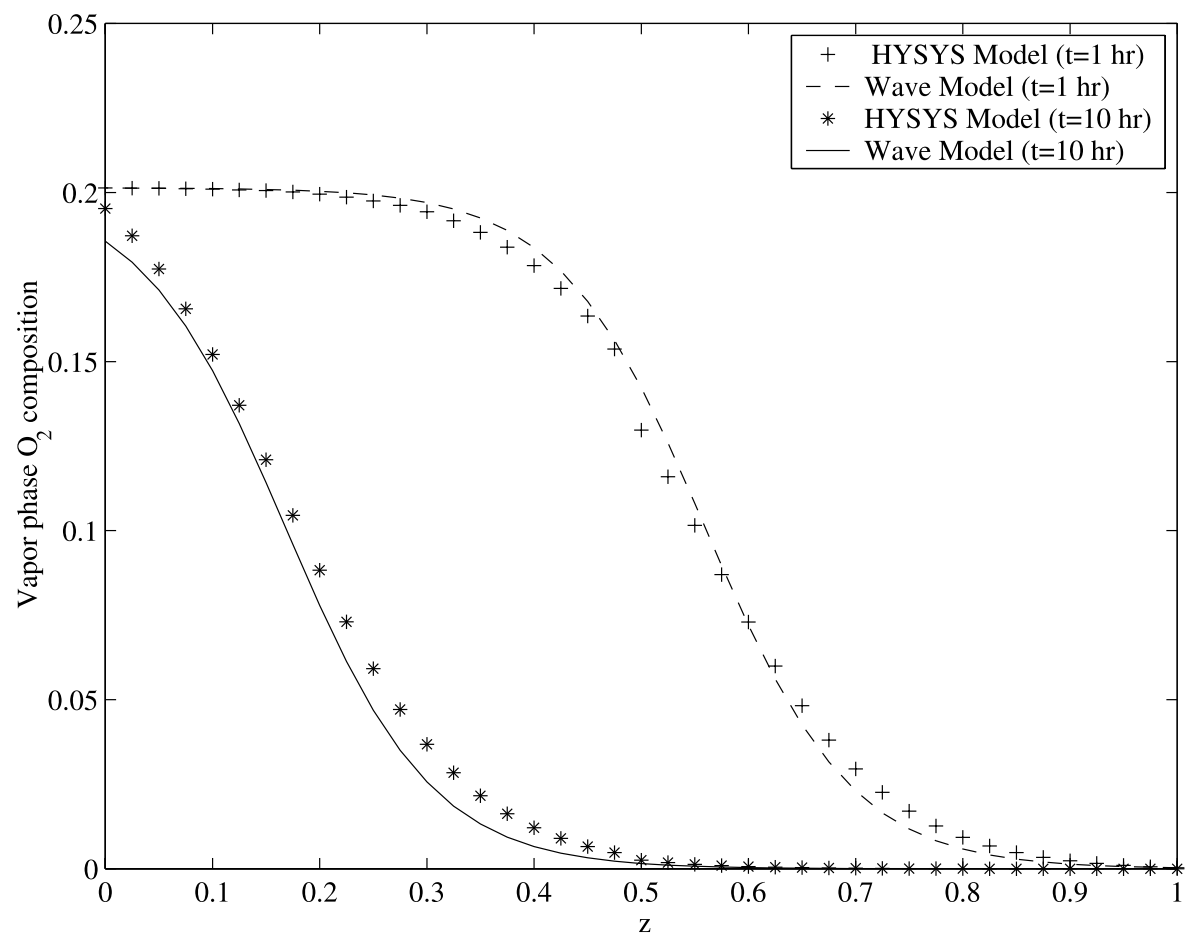

Fig. 13. Composition profile propagation corresponding to Fig. 12.

stream pressure is equal to the reboiler pressure $P_{\mathrm{r}}$. While more sophisticated enthalpy correlations are available [20], both liquid and vapor enthalpies are assumed to be a function only of temperature and composition:

$h\left(T, x_{i}\right)=\sum_{i=1}^{2} x_{i}\left(h_{i}^{0}+\int_{T^{\circ}}^{T} C p_{i} \mathrm{~d} T\right)$

$C p_{i}=C p_{i_{A}}+C p_{i_{B}} T+C p_{i_{C}} T^{2}$

where $h_{\mathrm{i}}^{0}$ is the enthalpy of pure component $i$ at the reference temperature $T^{\circ}$ and $C p_{i}$ is chosen as a second order polynomial in $T$. The correlation parameters $\left(C p_{i_{A}}, C p_{i_{B}}, C p_{i_{C}}\right)$ for the liquid and vapor phases are estimated from enthalpy data generated from HYSYS at the pressure $P_{\mathrm{r}}$ and over a reasonable range of operating temperatures.

\section{A.2. Reboiler model}

The reboiler model equations are:

$\frac{\mathrm{d} M_{1}}{\mathrm{~d} t}=\left(1-q_{\mathrm{v}}\right) F_{\mathrm{s}}-F_{\mathrm{V}}-F_{\mathrm{r} 1}$

$$
\begin{aligned}
\frac{\mathrm{d} M_{\mathrm{v}}}{\mathrm{d} t}=q_{\mathrm{v}} & F_{\mathrm{s}}+F_{\mathrm{V}}-F_{\mathrm{rv}} \\
\frac{\mathrm{d} M_{1} x_{\mathrm{r}}}{\mathrm{d} t}= & \left(1-q_{\mathrm{v}}\right) F_{\mathrm{s}} x_{N_{2}}^{\mathrm{v}}+\left(F_{\mathrm{V}}+F_{\mathrm{L}}\right) x_{\mathrm{r}}-F_{\mathrm{L}} x_{N_{2}}^{\mathrm{L}} \\
& -F_{\mathrm{r} 1} x_{\mathrm{r}} \\
\frac{\mathrm{d} M_{\mathrm{v}} y_{\mathrm{r}}}{\mathrm{d} t}= & q_{\mathrm{v}} F_{\mathrm{s}} y_{\mathrm{N}_{2}}^{\mathrm{v}}+\left(F_{\mathrm{V}}+F_{\mathrm{L}}\right) x_{\mathrm{r}}-F_{\mathrm{L}} x_{\mathrm{N}_{2}}^{\mathrm{L}}-F_{\mathrm{rv}} y_{\mathrm{r}}
\end{aligned}
$$

$$
\begin{aligned}
\frac{\mathrm{d} M_{1} h_{1}\left(T_{\mathrm{r}}, x_{\mathrm{r}}\right)}{\mathrm{d} t}= & \left(1-q_{\mathrm{v}}\right) F_{\mathrm{s}} h_{1}\left(T_{\mathrm{v}}, x_{\mathrm{N}_{2}}^{\mathrm{v}}\right)-F_{\mathrm{v}} h_{\mathrm{v}}\left(T_{\mathrm{r}}, x_{\mathrm{r}}\right) \\
& -F_{\mathrm{L}} h_{1}\left(T_{\mathrm{r}}, x_{\mathrm{r}}\right)+F_{\mathrm{L}} h_{1}\left(T_{\mathrm{r}}, x_{N_{2}}^{\mathrm{L}}\right) \\
& -F_{\mathrm{r} 1} h_{1}\left(T_{\mathrm{r}}, x_{\mathrm{r}}\right)+Q
\end{aligned}
$$

$y_{\mathrm{N}_{2}}^{\mathrm{V}} P_{\mathrm{r}}=P_{\mathrm{N}_{2}}^{\mathrm{sat}}\left(T_{\mathrm{r}}\right) x_{\mathrm{N}_{2}}^{\mathrm{L}}$

$y_{\mathrm{O}_{2}}^{\mathrm{V}} P_{\mathrm{r}}=P_{\mathrm{O}_{2}}^{\mathrm{sat}}\left(T_{\mathrm{r}}\right) x_{\mathrm{O}_{2}}^{\mathrm{L}}$

$x_{\mathrm{r}}\left(F_{\mathrm{L}}+F_{\mathrm{V}}\right)=F_{\mathrm{V}} y_{\mathrm{N}_{2}}^{\mathrm{V}}-F_{\mathrm{L}} x_{\mathrm{N}_{2}}^{\mathrm{L}}$

$\left(1-x_{\mathrm{r}}\right) F_{\mathrm{s}}=F_{\mathrm{V}} y_{\mathrm{O}_{2}}^{\mathrm{V}}-F_{\mathrm{L}} x_{\mathrm{O}_{2}}^{\mathrm{L}}$

$x_{\mathrm{N}_{2}}^{\mathrm{L}}+x_{\mathrm{O}_{2}}^{\mathrm{L}}=1$ 
$\frac{F_{\mathrm{L}}}{F_{\mathrm{V}}}=r$

where $M_{1}$ and $M_{\mathrm{v}}$ are the liquid and vapor molar holdups in the reboiler, respectively; $F_{\mathrm{rl}}$ and $F_{\mathrm{rv}}$ are the liquid and vapor flow rates leaving the reboiler, respectively; the nitrogen compositions of these two streams are denoted $x_{\mathrm{r}}$ and $y_{\mathrm{r}}$; the nitrogen and oxygen compositions associated with the flows $F_{\mathrm{V}}$ and $F_{\mathrm{L}}$ are denoted $y_{\mathrm{N}_{2}}^{\mathrm{V}}, y_{\mathrm{O}_{2}}^{\mathrm{V}}, x_{\mathrm{N}_{2}}^{\mathrm{L}}$, and $x_{\mathrm{O}_{2}}^{\mathrm{L}} ; T_{\mathrm{r}}$ is the reboiler temperature; $Q$ is the heat transfer rate between the condenser and reboiler; and $r$ is called the priming ratio and is assumed to be constant.

Equations (A9)-(A12) can be manipulated to yield nonlinear ordinary differential equations for the reboiler level $\left(H_{\mathrm{r}}\right)$, the reboiler pressure $\left(P_{\mathrm{r}}\right)$, and the reboiler liquid and vapor phase compositions $\left(x_{\mathrm{r}}, y_{\mathrm{r}}\right)$ :

$$
\begin{aligned}
& \frac{\mathrm{d} H_{\mathrm{r}}}{\mathrm{d} t}= \\
& \frac{\left(1-q_{\mathrm{v}}\right) F_{\mathrm{s}}-F_{\mathrm{v}}-F_{\mathrm{r} 1}-\left(\rho_{\mathrm{N}_{2}}-\rho_{\mathrm{O}_{2}}\right) / \rho\left(x_{\mathrm{r}}\right)\left[\left(1-q_{\mathrm{v}}\right) F_{\mathrm{s}}\left(x_{\mathrm{N}_{2}}^{\mathrm{v}}-x_{\mathrm{r}}\right)+F_{\mathrm{L}}\left(x_{\mathrm{N}_{2}}^{\mathrm{L}}-x_{\mathrm{r}}\right)\right]}{\rho\left(x_{\mathrm{r}}\right) V_{\mathrm{r}}}
\end{aligned}
$$

$$
\frac{\mathrm{d} P_{\mathrm{r}}}{\mathrm{d} t}=\frac{R T_{\mathrm{r}}}{V_{\mathrm{r}}\left(1-H_{\mathrm{r}}\right)}\left(V+q_{\mathrm{v}} F_{\mathrm{s}}-F_{\mathrm{rv}}+\frac{P_{\mathrm{r}} V_{\mathrm{r}}}{R T_{\mathrm{r}}} \frac{\mathrm{d} H_{\mathrm{r}}}{\mathrm{d} t}\right)
$$

$$
\frac{\mathrm{d} x_{\mathrm{r}}}{\mathrm{d} t}=\frac{\left(1-q_{\mathrm{v}}\right) F_{\mathrm{s}}\left(x_{\mathrm{v}}-x_{\mathrm{r}}\right)+F_{\mathrm{L}}\left(x_{\mathrm{N}_{2}}^{\mathrm{L}}-x_{\mathrm{r}}\right)}{\rho\left(x_{\mathrm{r}}\right) H_{\mathrm{r}} V_{\mathrm{r}}}
$$

$$
\begin{aligned}
\frac{\mathrm{d} y_{\mathrm{r}}}{\mathrm{d} t}= & \frac{R T_{\mathrm{r}}}{P_{\mathrm{r}} V_{\mathrm{r}}\left(1-H_{\mathrm{r}}\right)}\left[q_{\mathrm{v}} F_{\mathrm{s}}\left(y_{\mathrm{N}_{2}}^{\mathrm{v}}-y_{\mathrm{r}}\right)+F_{\mathrm{v}}\left(x_{\mathrm{r}}-y_{\mathrm{r}}\right)\right. \\
& \left.+F_{\mathrm{L}}\left(x_{\mathrm{r}}-x_{\mathrm{N}_{2}}^{\mathrm{L}}\right)\right]
\end{aligned}
$$

where $V_{\mathrm{r}}$ is the reboiler volume and $R$ is the gas constant. Note that the ideal gas law has been used to calculate the pressure from the vapor phase molar holdup. The liquid phase energy balance Eq. (A.13) can be transformed into an algebraic equation by substitution of the derivatives $\mathrm{d} M_{1} / \mathrm{d} t$ Eq. (A.9), $\mathrm{d} x_{\mathrm{r}} / \mathrm{d} t$ Eq. (A.22) and $\mathrm{d} T_{\mathrm{r}} / \mathrm{d} t$. We invoke the quasi-steady-state assumption for the reboiler temperature $\left(\mathrm{d} T_{\mathrm{r}} / \mathrm{d} t \approx 0\right)$, because the temperature dynamics are much faster than the level and composition dynamics. A rigorous description of the temperature dynamics based on an overall energy balance for the re- boiler is not pursued because the resulting model equations are complex. The reboiler temperature along with the vaporizing and returning liquid stream flow rates and compositions are calculated from the liquid phase energy balance and flash equations (A13)-(A19).

\section{References}

[1] L.S. Balasubramhanya, F.J. Doyle, Nonlinear control of a high-purity distillation column using a travelling-wave model, AIChE J. 43 (1997) 703-714.

[2] L.S. Balasubramhanya, F.J. Doyle, Nonlinear modelbased control of a batch reactive distillation column, J. Process Control 10 (2000) 209-218.

[3] A. Benallou, D.E. Seborg, D.A. Mellichamp, Dynamic compartmental models for separation processes, AIChE J. 32 (1986) 1067-1078.

[4] E.D. Gilles, B. Retzbach, Reduced models and control of distillation columns with sharp temperature profiles, IEEE Trans. Autom. Control 28 (1983) 628-630.

[5] M. Han, S. Park, Control of high-purity distillation column using a nonlinear wave theory, AIChE J. 39 (1993) 787-796.

[6] M. Han, S. Park, Startup of distillation columns using profile position control based on a nonlinear wave model, Ind. Eng. Chem. Res. 38 (1999) 1565-1574.

[7] F. Helfferich, G. Klein, Multicomponent Chromatography: Theory of Interference, Marcel Dekker, New York, 1970.

[8] Y.-L. Hwang, F.G. Helfferich, Dynamics of continuous countercurrent mass transfer processes-I. Single component linear systems, Chem. Eng. Sci. 42 (1987) 105-123.

[9] Y.-L. Hwang, Nonlinear wave theory for dynamics of binary distillation columns, AIChE J. 37 (1991) 705-723.

[10] Y.-L. Hwang, F.G. Helfferich, Dynamics of continuous countercurrent mass transfer processes-II. Single-component systems with nonlinear equilibria, Chem. Eng. Sci. 43 (1988) 1099-1114.

[11] A. Kienle, Lower-order dynamic models for ideal multicomponent distillation process using nonlinear wave propagation theory, Chem. Eng. Sci. 55 (2000) 1817-1828.

[12] P.V. Kokotovic, Application of singular perturbation techniques to control problems, SIAM Rev. 26 (1984) $501-550$.

[13] J. Levine, P. Rouchon, Quality control of binary distillation columns via nonlinear aggregated models, Automatica 27 (1991) 463-480.

[14] W.L. Luyben, Profile position control of distillation columns with sharp temperature profiles, AIChE J. 18 (1972) 238 .

[15] W. Marquardt, Nonlinear model reduction for binary distillation, in: Proceedings IFAC Control of Distillation Columns and Chemical Reactors, Bournemouth, UK, 1986, pp. 123-128. 
[16] W. Marquardt, M. Amrhein, Development of a linear distillation model from design data for process control, Computers Chem. Eng. 18 (1994) S349-S353.

[17] E.S. Meadows, J.B. Rawlings, Model predictive control, in: M.A. Henson, D.E. Seborg (Eds.), Nonlinear Process Control, Prentice-Hall, Engelwood Cliffs, NJ, 1997, pp. 223-310 chapter 5 .

[18] R.H. Perry, D.W. Green, J.O. Maloney, Perry's Chemical Engineer's Handbook, McGraw-Hill, New York, NY, 1984.
[19] A. Rhem, F. Allgower, Nonlinear $H_{\infty}$-control of a high distillation column, in: UKACC International Conference on Control'96, Exeter, UK, 1996, pp. 11781183.

[20] R.C. Reid, J.M. Prausnitz, B.E. Poling, The Properties of Gases and Liquids, McGraw-Hill, New York, 1987.

[21] H.-K. Rhee, R. Aris, N.R. Amundson, First-order Partial Differential Equations: Vol. I Theory and Application of Single Equations, Prentice-Hall, Englewood Cliffs, NJ, 1986. 